\section{Feeding problems in healthy young children: prevalence, related factors and feeding practices}

\author{
Banchaun Benjasuwantep, \\ Suthida Chaithirayanon, \\ Monchutha Eiamudomkan \\ Department of Pediatrics, Faculty of \\ Medicine, Srinakharinwirot University, \\ Thailand
}

\section{Abstract}

The aim of this study was to determine the prevalence, characteristics, and factors related to feeding problems among normal children, and the differences in feeding practices between those with and without feeding problems. Caregivers of 402 healthy children aged between one and four years of age were interviewed by pediatricians involved in the research. Data included the child's medical history, food intake within a day, and feeding behaviors and practices. Parental socio-economic and demographic information, as well as information on parental education and occupation, and their concerns about feeding their children, was collected. Physical examination and anthropometric measurements were taken. The percentage of children identified as having feeding problems was $26.9 \%$. The first child of a family had an increased risk of having feeding problems $[\mathrm{P}=0.032$, odds ratio $1.68,95 \%$ confidence interval (95\%CI) 1.04-2.71]. Children with feeding problems were fed less frequently, were less likely to be fed at their own table or at the family table, and had mealtimes longer than 30 min when compared with children without feeding problems $(\mathrm{P}=0.015,0.004$ and 0.025 , respectively). The results highlight that feeding problems in normally developing children are common. During consultations about feeding issues, pediatricians should focus on families with a first child. Topics such as frequency of meals per day, duration of mealtimes, and appropriate places for feeding should be discussed.

\section{Introduction}

Feeding problems are common in children. Approximately 20-50\% of normally developing children, ${ }^{1-7}$ and $70-89 \%$ of children with developmental disabilities, ${ }^{8-10}$ are reported to experience some type of feeding problems.
However, determining the prevalence of feeding problems may be complicated since there is no universally accepted definition or classification system.

There are some diagnostic criteria for identifying feeding problems.11,12 The Diagnostic and Statistical Manual of Mental Disorders (4th ed. text revision, DSM IV-TR) describes feeding disorders of infancy or early childhood as a persistent feeding disturbance and either a failure to gain weight or a significant loss of weight for at least one month without significant medical conditions or lack of available food. ${ }^{12}$ Crist and Napier-Phillips used the Behavioral Pediatrics Feeding Assessment Scale (BPFAS) to divide problematic feeding behavior into 5 types: 13 i) picky eaters; ii) toddler refusal-general; iii) toddler refusal-textured food; iv) older children refusal-general; and v) stallers. The BPFAS, a standardized feeding assessment questionnaire, has 35 items with descriptions of a child's behaviors and a parent's feelings of or strategies for dealing with feeding problems. The parents are requested to answer whether their child's behavior is a problem and how often the behavior occurs on a 5 -point Likert scale from never to always. Kerzner recently provided a guide for pediatricians to evaluate feeding difficulties in young children. ${ }^{14} \mathrm{He}$ suggested taking the child's history and utilizing anthropometric measurements and physical examination in order to identify red flags or markers. For example, dysphagia, odynophagia, unco-operative swallowing, crying during feeding, vomiting and diarrhea, eczema, failure to thrive, and developmental disability, were used as signs to diagnose and treat an underlying pathology of feeding difficulties. He also recommends obtaining additional details of feeding practices, problematic behaviors, and parent-child feeding interaction as necessary. The child is then classified into one of 4 categories: i) limited appetite (4 subtypes: normal child with misperceived limited appetite, vigorous child with little interest in feeding, depressed child with little interest in feeding, and child with poor appetite due to organic disease); ii) highly selective intake; iii) crying which interferes with feeding (colic); and iv) fear of feeding. Dovey et al. ${ }^{15}$ presented 5 categories of food refusal behaviors: i) learning-dependent food refusal; ii) medical complicationrelated food refusal; iii) selective food refusal; iv) fear-based food refusal; and v) appetite awareness and autonomy-based food refusal.

Previous studies had applied different classifications to determine the prevalence of feeding problems. Esparo et al. 16 assessed 851 children aged 3-6 years based on DSM IV criteria to analyze feeding problems and found a prevalence of $4.8 \%$. Jacobi et al. $^{1}$ demonstrated
Correspondence: Banchaun Benjasuwantep, Department of Pediatrics, Faculty of Medicine, HRH Princess Maha Chakri Sirindhorn Medical Center, 62 Mui 7, Rangsit-Nakhon Nayok road, Onkharak, Nakhon Nayok 26120, Thailand.

Tel. +66.37.395085.10901.

Fax: +66.37.395085.10901.

E-mail: banchaun_b@yahoo.com,

banchaun@gmail.com

Key words: children, feeding problems, prevalence.

Acknowledgments: this study received a grant from the Faculty of Medicine, Srinakharinwirot University. The authors are grateful to Dr. Suthee Rattanamongkolgul for his contributions to the manuscript and statistical analyses, and to all the parents and children who participated in this study.

Contributions: BB, data collecting, population enrollment and assessment, data analysis and writing the manuscript; SC, ME, population assessment, data analysis and interpretation and revising the article.

Funding: the study was supported by a grant from the Faculty of Medicine, Srinakharinwirot University.

Conference presentation: a preliminary report of this study was presented at the $8^{\text {th }}$ Congress of Asian Society for Pediatric Research, May 17-19, 2012, Seoul, South Korea.

Conflict of interests: the authors declare no potential conflict of interests.

Received for publication: 23 November 2012.

Revision received: 7 March 2013.

Accepted for publication: 11 March 2013.

This work is licensed under a Creative Commons Attribution NonCommercial 3.0 License (CC BYNC 3.0).

(C) Copyright B. Benjasuwantep et al., 2013 Licensee PAGEPress, Italy

Pediatric Reports 2013; 5:e10

doi:10.4081/pr.2013.e10

$21 \%$ of parent-reported picky eaters using the Stanford Feeding Questionnaire and laboratory-based measurement in 135 infants. Moreover, some studies established the prevalence of feeding problems based on the perception of caregivers. Reau et al. ${ }^{3}$ surveyed 130 infants and 151 toddlers on problematic feeding behavior (PFB) and found that the most common infant and toddler PFB was not always hungry at mealtime at $33 \%$ and $52 \%$, respectively. Carruth et al. ${ }^{2}$ presented the percentage of picky eaters in children aged 4-24 months as $19 \%$ to $50 \%$ according to the perception of caregivers. 
The typical onset of problems related to feeding occurs from six months to four years of age. 17 Therefore, the present study aims to address the proportion and nature of feeding problems in children from one to four years of age in a well baby clinic setting, as well as to determine the risk factors and feeding practices which differentiate children with feeding problems from those without.

\section{Materials and Methods}

Caregivers of normal children aged 1-4 years attending the well baby clinic of the HRH Princess Maha Chakri Sirindhorn Medical Center from August 2010 to January 2012 were interviewed by the developmental-behavioral pediatrician (BB) or one of 2 general pediatricians (CS and EM) after informed consent. The study was approved by the Research Ethics Committee of the Faculty of Medicine, Srinakharinwirot University. Information was collected regarding: i) parental socio-economic and demographic characteristics; ii) child's medical history; iii) types and amount of food, including the amount of milk and formula taken within a day, along with the variety of foods within each food group the child accepted; iv) child's feeding issues, which cover child feeding history, feeding behaviors, feeding practices, and caregivers' concerns about feeding. Each child underwent physical examination and anthropometric measurements were taken. Children with significant underlying medical problems, developmental disabilities or who were born premature were excluded from the study.

Kerzner's ${ }^{14}$ description of feeding difficulties was used to evaluate whether children had feeding problems. Feeding difficulties were categorized as: normal child with misperceived limited appetite, vigorous child with little interest in feeding, highly selective intake, and excessive or irrational fear of feeding. A normal child with misperceived limited appetite refers to a normal child who had limited appetite but whose appetite was still commensurate with the child's size and nutrition needs. In these cases, the caregivers' excessive concern about growth expectations led to coercive feeding methods that adversely affected the child. A vigorous child with little interest in feeding refers to a child who has refused to eat adequate amounts of food for at least one month. Typically, the onset of food refusal occurs during the transition to spoon- and self-feeding; these children were alert, active, inquisitive and easily distracted from eating by their surrounding environment. A child who is classified as highly selective refers to a child who consistently refused specific food items of a particular taste, texture, smell or appearance; the behavior of children in this group went beyond the normal resistance to the introduction of new food. These children might lack feeding skills considered appropriate for their age, such as only consuming soft-textured food. In this study, Carruth and Skinner's description of children's oral motor development as it relates to feeding behavior was used to evaluate the feeding skills of children.18 Excessive or irrational fear of feeding refers to children who refused to eat by crying or refusing to open their mouths. These children typically had a history of noxious oral experiences, e.g. choking.

\section{Statistical analyses}

A sample size of 402 was taken. For categorical data, a $\chi^{2}$ test was used to assess the significant association of variables between normal and feeding problems groups. A t-test was performed with continuous data. Logistical regression was used to analyze the relationship between the child's birth order and the probability of having feeding problems, and to calculate odds ratios and 95\% confidence interval. $\mathrm{P}<0.05$ was considered significant.

\section{Results}

\section{Study population and socio-demographic data of normal and feeding-problem children}

Of the 402 children, 214 were boys (53.2\%) and 188 were girls $(46.8 \%)$. The mean age at presentation was $22.93 \pm 9.62$ months. Two hundred and sixty-seven children (66.4\%) were aged 12-24 months, 93 (23.1\%) aged 2536 months, and 42 (10.5\%) aged 37-48 months.

There was no significant difference in age, gender, birth weight, caregiver, family income, age of father and mother, maternal education and occupation between normal and feedingproblem children $(\mathrm{P}=0.27,0.18,0.21,0.27$,

Table 1. Comparison of socio-demographic characteristics between normal and feedingproblem children.

\begin{tabular}{lccc} 
Demographic data & $\begin{array}{c}\text { Normal child } \\
(\mathrm{n}=294)\end{array}$ & $\begin{array}{c}\text { Feeding-problem child } \\
(\mathrm{n}=108)\end{array}$ & $\mathrm{P}$ \\
Age, mean \pm SD, months & $23.24 \pm 9.96$ & $22.06 \pm 8.61$ & 0.272 \\
Birth weight, mean $\pm \mathrm{SD}, \mathrm{g}$ & $3065.25 \pm 376.81$ & $3007.71 \pm 403.34$ & 0.184 \\
\hline Family income, mean \pm SD, baht & $24728.42 \pm 22549.87$ & $26805.56 \pm 30413.19$ & 0.462 \\
Age of father, mean \pm SD, years & $33.87 \pm 7.22$ & $34.18 \pm 7.68$ & 0.714 \\
\hline Age of mother, mean $\pm S D$, years & $30.5 \pm 6.22$ & $29.96 \pm 6.08$ & 0.439 \\
\hline
\end{tabular}

Table 2. Percentage of feeding problems according to socio-demographic characteristics, odds ratios and $95 \%$ confidence interval in healthy children attending the well baby clinic of the HRH Princess Maha Chakri Sirindhorn Medical Center.

\begin{tabular}{|c|c|c|c|c|c|c|c|}
\hline \multirow[t]{2}{*}{ Variables } & \multirow[t]{2}{*}{ Categories } & \multicolumn{3}{|c|}{ Feeding problems } & \multirow[t]{2}{*}{ Odds ratio } & \multirow[t]{2}{*}{$95 \% \mathrm{CI}$} & \multirow[t]{2}{*}{$\mathbf{P}$} \\
\hline & & Normal & n & $\%$ & & & \\
\hline \multirow{2}{*}{ Sex } & Female & 188 & 45 & 23.9 & 1.00 & \multirow{2}{*}{$0.85-2.07$} & \multirow{2}{*}{0.214} \\
\hline & Male & 214 & 63 & 29.4 & 1.33 & & \\
\hline \multirow{2}{*}{ Birth order } & Second or later child & 149 & 32 & 21.5 & 1.00 & \multirow{2}{*}{$1.04-2.71$} & \multirow{2}{*}{$0.032^{*}$} \\
\hline & First child & 238 & 75 & 31.5 & 1.68 & & \\
\hline \multirow[t]{2}{*}{ Caregiver } & Others & 135 & 31 & 23 & 1.00 & \multirow[t]{2}{*}{$0.81-2.16$} & \multirow[t]{2}{*}{0.271} \\
\hline & Mother & 234 & 66 & 28.2 & 1.32 & & \\
\hline \multirow{2}{*}{ Maternal education } & $\leq$ grade 12 & 180 & 45 & 25 & 1.00 & \multirow{2}{*}{$0.77-1.87$} & \multirow[b]{2}{*}{0.431} \\
\hline & $>$ grade 12 & 221 & 63 & 28.5 & 1.2 & & \\
\hline \multirow{2}{*}{ Maternal occupation } & Housewife & 119 & 30 & 25.2 & 1.00 & \multirow{2}{*}{$0.69-1.83$} & \multirow{2}{*}{0.651} \\
\hline & Worker & 281 & 77 & 27.4 & 1.12 & & \\
\hline
\end{tabular}

CI, confidence intervals.

${ }^{*} \mathrm{P}<0.05$ statistically significant. 
$0.46,0.71,0.44,0.43$ and 0.65 , respectively) (Tables 1 and 2). However, the first child of a family was found to have a significant risk of being a feeding-problem child $(\mathrm{P}=0.03,0 \mathrm{R}$ 1.68: 95\%CI: 1.04-2.71) (Table 2).

\section{Prevalence and distribution of feeding problems in each age group}

The overall prevalence of feeding problems was $26.9 \%$ (95\%CI: 22.57-31.23). There was a greater prevalence among boys $(29.4 \%, 95 \% \mathrm{CI}$ : 23.3-35.5) than girls (23.9\%, CI:17.8-30) but this was not statistically significant $(\mathrm{P}=0.214)$. Feeding problems were most prevalent (28.1\%) in the second year of life and gradually decreased during the third and fourth years (26.9\% and 19\%, respectively) (Figure 1).

Table 3 demonstrates the varied types of feeding problems and their occurrence. The highly selective intake category was found to be the most prevalent at $15.4 \%$. Prevalence of vigorous children with little interest in feeding, normal children with misperceived limited appetites, and those with excessive or irrational fear of feeding was $6.7 \%, 4.5 \%$ and $0.2 \%$, respectively. Within the group of vigorous children with little interest in feeding, 6 (1.5\%) children weighed less than the 3 rd percentile on the Thai growth curve for their age.

\section{Comparison of feeding practices between normal and feeding-problem children}

The study illustrated that children with feeding problems had significantly different feeding practices from normal children. They were fed less frequently, were less likely to be fed at their own table or at the family table, and had mealtimes longer than 30 min $(\mathrm{P}=0.015,0.004$ and 0.025 , respectively) (Tables 4 and 5 ). In addition, the feeding problem group had longer mealtime duration than normal children, but this was not statistically significant (mean 25.19 and $22.96 \mathrm{~min}$, respectively) $(\mathrm{P}=0.182)$.

We explored the issue of a regular feeding site and found that one-third of Thai children did not have a definite place for feeding. Feeding-problem children (42.6\%) were found to have no definite feeding site more often than normal children (31\%). In contrast, normal children (45.6\%) were fed at appropriate sites, such as in a high chair or at the child's table or at the family table, more frequently than feeding-problem children (29.6\%) (Table 6).

\section{Discussion}

The present study showed that the prevalence of feeding problems in toddlers and early pre-schoolers was $26.9 \%$. This finding con- firms the result of previously published reports. 4,19,20 However, only 6 children in the vigorous child with little interest in feeding group experienced feeding difficulty as their weight for age was below the $3^{\text {rd }}$ percentile demarcation on the Thai child growth curve which is consistent with the criteria for diag-

nosing failure to thrive. ${ }^{21}$ This showed that using growth curves to identify feeding problems may not be sufficiently accurate in general pediatric practice. The percentage of children considered to have feeding problems in our study gradually decreased from $28.1 \%$ to $19 \%$ from the second to the fourth year of life.

Table 3. Types of feeding problems $(n=402)$.

\begin{tabular}{lcc} 
Type of feeding problems & N & $\%$ \\
Normal child with misperceived limited appetite & 18 & 4.48 \\
Vigorous child with little interest in feeding & 27 & 6.72 \\
\hline Highly selective intake & 62 & 15.43 \\
Excessive or irrational fear of feeding & 1 & 0.25 \\
\hline Total & 108 & 26.9 \\
\hline
\end{tabular}

Table 4. Feeding practices in normal children compared with children with feeding problems.

\begin{tabular}{lccc} 
Feeding practices & $\begin{array}{c}\text { Normal children } \\
(\mathrm{n}=294)\end{array}$ & $\begin{array}{c}\text { Feeding-problem } \\
\text { children }(\mathrm{n}=108)\end{array}$ & $\mathrm{P}$ \\
\hline Frequency of meals, mean $\pm \mathrm{SD}$, time & $2.93 \pm 0.54$ & $2.74 \pm .74$ & $0.015^{*}$ \\
Mealtime duration, mean $\pm \mathrm{SD}$, min & $22.96 \pm 10.97$ & $25.19 \pm 16$ & 0.182 \\
\hline Frequency of snacks, mean $\pm \mathrm{SD}$, time & $2.31 \pm 0.97$ & $2.49 \pm 1.20$ & 0.163 \\
Volume of milk/day, mean $\pm \mathrm{SD}, \mathrm{oz}$ & $29.63 \pm 12.57$ & $30.57 \pm 13.14$ & 0.531 \\
\hline Volume of milk at night/day, mean $\pm \mathrm{SD}, \mathrm{oz}$ & $13.07 \pm 9.52$ & $13.99 \pm 7.35$ & 0.471
\end{tabular}

$* \mathrm{P}<0.05$ statistically significant.

Table 5. Comparison of feeding methods between normal and feeding-problem children.

\begin{tabular}{|c|c|c|c|c|c|}
\hline Feeding practices & $\begin{array}{c}\text { Norma } \\
\text { (n } \\
\text { N }\end{array}$ & $\begin{array}{l}\text { ildren } \\
\text { 4) } \\
\%\end{array}$ & Feeding-pr & $\begin{array}{l}\text { D8) } \\
0 \%\end{array}$ & $\mathbf{P}$ \\
\hline Nighttime feeder & 209 & 71.1 & 86 & 79.6 & 0.086 \\
\hline Prolongs mealtime duration ( $>30 \mathrm{~min}$ ) & 20 & 6.8 & 15 & 13.9 & $0.025^{*}$ \\
\hline Bottle fed $^{\circ}$ & 180 & 82.6 & 71 & 86.6 & 0.402 \\
\hline $\begin{array}{l}\text { Fed at child's table/table } \\
\text { with other family members }\end{array}$ & 134 & 45.6 & 32 & 29.6 & $0.004^{*}$ \\
\hline Self-feeder & 205 & 69.7 & 65 & 60.2 & 0.071 \\
\hline
\end{tabular}

${ }^{*} \mathrm{P}<0.05$ statistically significant. ${ }^{\circ}$ Data were missing for 102 children: 76 from the normal group and 26 from the feeding-problem group.

Table 6. Feeding site in normal and feeding-problem children.

\begin{tabular}{lcccc} 
Feeding site & \multicolumn{2}{c}{ Normal } & Feeding-problem children \\
& N & $\%$ & N & $\%$ \\
High chair or child's table & 38 & 12.9 & 12 & 11.1 \\
Table with other family members & 96 & 32.7 & 20 & 18.5 \\
\hline In front of TV & 28 & 9.5 & 13 & 12 \\
No definite place to feed & 91 & 31 & 46 & 42.6 \\
\hline Fed while walking & 18 & 6.1 & 13 & 12 \\
Fed on floor & 23 & 7.8 & 4 & 3.7 \\
\hline Total & 294 & 100 & 108 & 100 \\
\hline
\end{tabular}




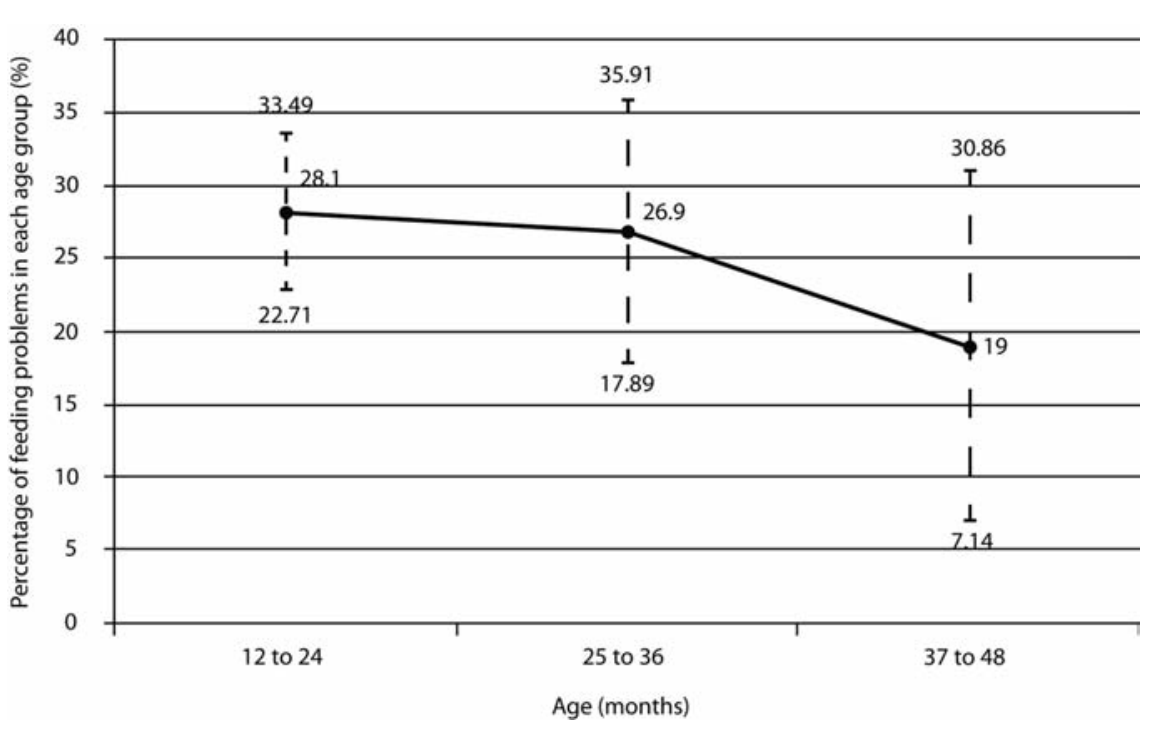

Figure 1. Prevalence of distribution of feeding problems in each age group.

This may be due to several factors. Firstly, the second year of life corresponded to a transitional period from feeding liquid diet to solid food consumption in which children need to develop oral motor control and acquire less sensitivity in the lips and mouth in order to manipulate and accept different types of food. Therefore, children who had minimal experience and practice would experience feeding problems at this age. Secondly, children in this age group are concerned with a sense of autonomy, seek independence at mealtime, and are easily distracted during feeding as they explore their surrounding environment. This unique developmental stage would only intensify any problems during feeding, increasing the problem in this age range. Thirdly, feeding difficulties in children range from mild and transient to severe and chronic forms; transient problems would improve over time while severe problems would remain.

The most prevalent feeding problem in the present study was found to be highly selective intake (15.4\%). This may be because this encompasses several types of feeding problems, e.g. the selectivity of food by its taste, type and texture, and also a lack of developmentally appropriated feeding skills. Moreover, it must be remembered that we found $4.5 \%$ of the subjects were classified as normal with misperceived limited appetite. This finding indicated that some parents might be overly concerned about their child's weight or about feeding issues. As a result, we recommend that pediatricians place more emphasis on educating parents and caregivers about appropriate expectations for a normal growth pattern, nutrition requirements, and healthy feeding practices.

Contrary to results reported by Crist and Napier-Phillips, ${ }^{13}$ we found that the first child of a family had an increased risk of having feeding problems. This finding did, however, agree with that of Ramsay et al.;2 in their study, a higher percentage of the clinical nonmedical sample were first born children compared with the normative and clinical medical group. Inexperience and parents with misguided expectations might explain the risk for feeding problems. Thus, pediatricians should focus on providing advice on feeding to parents with a first child.

In the present study, there were some significant differences in feeding practice between normal and feeding-problem children. Feeding-problem children were fed less frequently, were less likely to be fed at their own table or at the family table, and had meal durations longer than $30 \mathrm{~min}$, compared with normal children. To our knowledge, few studies have addressed the association between feeding problems and feeding frequency or feeding site. However, the result of the significant correlation of mealtime length beyond $30 \mathrm{~min}$ with feeding difficulty was consistent with previous studies.3,4,13 We speculated that given the difficulties in getting children in the feeding-problem group to accept food, mealtimes were longer, less food was eaten, and feeding sites varied according to where the child would accept food.

\section{Conclusions}

Feeding problems are prevalent among healthy toddlers and early pre-schoolers in pediatric practice. Special attention should be given to parents with a first child even during a regular visit at the well baby clinic. The issues of meal frequency, mealtime duration and feeding site should be taken into consideration during pediatric consultation. Assistance and advice from the pediatrician will help to prevent and solve complicated feeding problems in the future.

\section{References}

1. Jacobi C, Agras WS, Bryson S, Hammer LD. Behavioral validation, precursors, and concomitants of picky eating in childhood. J Am Acad Child Adolesc Psychiatry 2003;42:76-84.

2. Carruth BR, Ziegler PJ, Gordon A, Barr SI. Prevalence of picky eaters among infants and toddlers and their caregivers' decisions about offering a new food. J Am Diet Assoc 2004;104:s57-64.

3. Reau NR, Senturia YD, Lebailly SA, Christoffel KK. Infant and toddler feeding patterns and problems: normative data and a new direction. Pediatric Practice Research Group. J Dev Behav Pediatr 1996;17:149-53.

4. Wright CM, Parkinson KN, Shipton D, Drewett RF. How do toddler eating problems relate to their eating behavior, food preferences, and growth? Pediatrics 2007; 120:e1069-75.

5. Udall JN Jr. Infant feeding: initiation, problems, approaches. Curr Probl Pediatr Adolesc Health Care 2007;37: 374-99.

6. Lumeng JC. Feeding and eating conditions. In: Wolraich ML, Drotar DD, Dworkin PH, Perrin EC (eds.) Developmental-behavioral pediatrics: evidence and practice. Philadelphia, PA: Mosby Elsvier; 2008. pp 757-67.

7. Lindberg L, Bohlin G, Hagekull B. Early feeding problems in a normal population. Int J Eat Disord 1991;10: 395-405.

8. Sullivan PB, Lambert B, Rose M, et al. Prevalence and severity of feeding and nutritional problems in children with neurological impairment: 0xford Feeding Study. Dev Med Child Neurol 2000;42:67480.

9. Williams PG, Dalrymple N, Neal J. Eating habits of children with autism. Pediatr Nurs 2000;26:259-64.

10. Reilly S, Skuse D, Poblete X. Prevalence of feeding problems and oral motor dysfunction in children with cerebral palsy: a community survey. J Pediatr 1996;129:877-82.

11. Levine A, Bachar L, Tsangen $Z$, et al. Screening criteria for diagnosis of infantile feeding disorders as a cause of poor feeding or food refusal. J Pediatr Gastroenterol Nutr 2011;52: 563-8.

12. American Psychiatric Association. Diagnostic and statistical manual of mental disorder, 4th ed. Text Revision. 
Arlington, VA, USA: American Psychiatric Association; 2000.

13. Crist W, Napier-Phillips A. Mealtime behaviors of young children: a comparison of normative and clinical data. J Dev Behav Pediatr 2001;22:279-86.

14. Kerzner B. Clinical investigation of feeding difficulties in young children: a practical approach. Clin Pediatr 2009;48:960-5.

15. Dovey TM, Farrow CV, Martin CI, et al. When does food refusal require professional intervention? Curr Nut Food Sci 2009;5:160-71.

16. Esparo G, Canals J, Jane C, et al. Feeding problems in nursery children: prevalence and psychosocial factors. Acta Paediatr 2004;93:663-8.

17. Aldridge VK, Dovey TM, Martin CI, Meyer C. Identifying clinically relevant feeding problems and disorders. J Child Health Care 2010;14:261-70.

18. Carruth BR, Skinner JD. Feeding behaviors and other motor development in healthy children (2-24 months). J Am Coll Nutr 2002;21:88-96.

19. Bernard-Bonnin AC. Feeding problems of infants and toddlers. Can Fam Physician 2006;52:1247-51.
20. Saarilehto $\mathrm{S}$, Lapinleimu $\mathrm{H}$, Keskinen $\mathrm{S}$, et al. Growth, energy intake, and meal pattern in five-year-old children considered as poor eaters. J Pediatr 2004;144:363-7.

21. Cole SZ, Lanham JS. Failure to thrive: an update. Am Fam Physician 2011;83: 82934.

22. Ramsay M, Martel C, Porporino M, Zygmuntowicz C. The Montreal children's hospital feeding scale: a brief bilingual screening tool for identifying feeding problems. Paediatr Child Health 2011;16: 147-e17. 